\title{
Synthesis of 3D Hexagram-Like Cobalt-Manganese Sulfides Nanosheets Grown on Nickel Foam: A Bifunctional Electrocatalyst for Overall Water Splitting
}

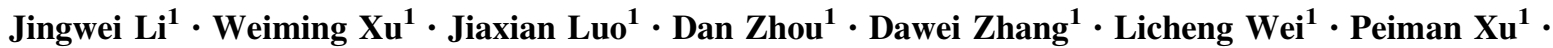 \\ Dingsheng Yuan ${ }^{1}$
}

Received: 13 August 2017/ Accepted: 17 September 2017/Published online: 13 October 2017

(C) The Author(s) 2017. This article is an open access publication

\section{Highlights}

- Cobalt-manganese sulfides grown on $\mathrm{Ni}$ foam $(\mathrm{CMS} / \mathrm{Ni})$ with three-dimensionally hexagram-like nanosheets structure were prepared via a solvothermal method.

- As-prepared CMS/Ni shows highly catalytic activity for OER and HER in basic medium and can catalyze water splitting by a $1.50 \mathrm{~V}$ dry battery.

\begin{abstract}
The exploration of low-cost and efficient bifunctional electrocatalysts for oxygen evolution reaction and hydrogen evolution reaction through tuning the chemical composition is strongly required for sustainable resources. Herein, we developed a bimetallic cobalt-manganese sulfide supported on $\mathrm{Ni}$ foam $(\mathrm{CMS} / \mathrm{Ni})$ via a solvothermal method. It has discovered that after combining with the pure $\mathrm{Co}_{9} \mathrm{~S}_{8}$ and $\mathrm{MnS}$, the morphologies of $\mathrm{CMS} / \mathrm{Ni}$ have modulated. The obtained three-dimensionally hexagram-like CMS/Ni nanosheets have a significant increase in electrochemical active surface area and charge transport ability. More than that, the synergetic effect of Co and $\mathrm{Mn}$ has also presented in this composite. Benefiting from these, the CMS/Ni electrode shows great performance toward hydrogen evolution reaction and oxygen evolution reaction in basic medium, comparing favorably to that of
\end{abstract}

Electronic supplementary material The online version of this article (doi:10.1007/s40820-017-0160-6) contains supplementary material, which is available to authorized users.

\footnotetext{
Dingsheng Yuan

tydsh@jnu.edu.cn

1 School of Chemistry and Materials Science, Jinan University, Guangzhou 510632, People's Republic of China
}
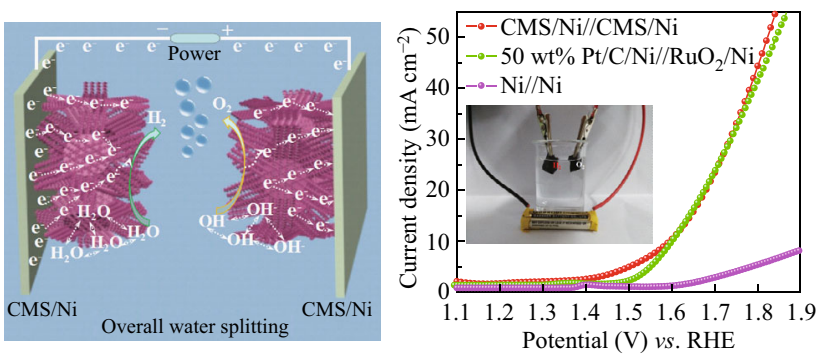

the pure $\mathrm{Co}_{9} \mathrm{~S}_{8} / \mathrm{Ni}$ and $\mathrm{MnS} / \mathrm{Ni}$. More importantly, this versatile CMS/Ni can catalyze the water splitting in a twoelectrode system at a potential of $1.47 \mathrm{~V}$, and this electrolyzer can be efficiently driven by a $1.50 \mathrm{~V}$ commercial dry battery.

Keywords Bifunctional electrocatalysts .

Oxygen evolution reaction - Hydrogen evolution reaction . Cobalt-manganese sulfides · Water splitting 


\section{Introduction}

Electrocatalytic water splitting has been regarded as the most promising and feasible technology to produce clean hydrogen fuel from aqueous solutions [1-3]. Hence, efficient electrocatalysts for both the oxygen evolution reaction (OER) at anodes and hydrogen evolution reaction (HER) at cathodes are urgently needed to reduce the energy consumption for overall water splitting [4-6]. Precious metal oxide (e.g., $\mathrm{RuO}_{2}, \mathrm{IrO}_{2}$ ) and noble metal (e.g., Pt, Ir, $\mathrm{Rh}$ ) electrocatalysts are so far known as the most efficient electrocatalysts toward OER and HER, respectively, but the high cost and scarcity have limited their widespread application [6, 7]. In this regard, tremendous efforts have been devoted to explore alternatively earth-abundant and cost-effective transition metal materials for OER or HER over the past several decades [8-22]. Unfortunately, these electrocatalysts are still not suitable for the real commercial applications. In addition, to simplify the overall water splitting system and cut the cost, developing highly efficient bifunctional electrocatalysts for both OER and HER in the same electrolyte, especially for alkaline electrolyte, has become one of the hottest issues recently [23]. Despite great advances have taken in this field [24-39], it is still in great demand to explore high-performance and non-noble bifunctional electrocatalysts for overall water splitting.

The catalytic activity could improve following the methods of chemical composition tuning and nanostructure modification [40-44]. On the one hand, to tailor the chemical composition of electrocatalysts, an effective way is doping with foreign atoms into the crystal lattice of materials. Following this way, the multicomponent or composite electrocatalysts would obtain [40-49]. The formation of different valence and electronic states of metal ions in these composites facilitates the adsorption and desorption of intermediates in the electrocatalysis process, and the synergistic effect between the metal ions is benefit for their catalytic activity. For example, Wu et al. [42] discovered the different valence states of $\mathrm{Ni}$ and synergistic effect between the metal ions in $\mathrm{Ni}_{3} \mathrm{ZnC}_{0.7}$, playing an important role in its catalytic activity for HER and OER. Yang et al. [50] synthe sized a $\mathrm{Co}(\mathrm{II})_{1-x} \mathrm{Co}(0)_{x / 3} \mathrm{Mn}(\mathrm{III})_{2 \times / 3} \mathrm{~S}$ nanoparticles combining with $\mathrm{B} / \mathrm{N}$-codoped mesoporous nanocarbon. They investigated the formation of different valence and electronic states of $\mathrm{Co}$ and $\mathrm{Mn}$ ions in facilitating the catalytic activity. On the other hand, optimizing the nanostructure of electrocatalysts can increase the quantity of effectively active sites. Comparing to nanoparticles materials, the electrocatalysts directly supported on conductive substrates, such as Ni foam, Ni mesh, Cu mesh, carbon cloth and carbon paper, with binder free can get to this point easily [41]. Recently, Ni foam has exhibited considerable potential in optimizing the nanostructure of materials [51-54]. It has a unique three-dimensional (3D) porous structure and high conductivity. For instance, our group [32] prepared urchinlike sphere arrays $\mathrm{Co}_{3} \mathrm{O}_{4}$ supported on 3D Ni foam showing great performance for HER and OER, which is benefit from its urchin-like nanostructure with rich mesopores and low charge-transfer resistance. Hu et al. [41] developed a Co-Mn carbonate hydroxide $(\mathrm{CoMnCH})$ nanosheet arrays on $\mathrm{Ni}$ foam exhibiting superior activity for HER and OER in basic medium.

Based on the above mentioned, a cobalt-manganese sulfides composite with a unique nanostructure was synthesized to exhibit an efficient catalytic performance for OER and HER. However, to the best of our knowledge, the cobaltmanganese sulfide with efficient catalystic performance has never been reported. Herein, the 3D hexagram-like CMS/Ni was prepared via a simple two-step hydrothermal method (Scheme 1). Firstly, the $\mathrm{CO}_{3}{ }^{2-}$ and $\mathrm{OH}^{-}$ions were released by the hydrolysis of urea and gradually co-precipitated with $\mathrm{Co}^{2+}$ and $\mathrm{Mn}^{2+}$ ions to form the 3D hexagram-like precursor CoMn-LDH/Ni. Subsequently, the 3D hexagram-like CMS/ Ni nanosheets were synthesized after a sulfurization process employing the thioacetamide (TAA) as the sulfur sources. The electrochemical catalytic activity of this composite was evaluated by linear sweep voltammetry, electrochemical impedance spectroscopy and chronoamperometry. The electrocatalytic performance of CMS/Ni for HER and OER is optimized with respect to those of the pure $\mathrm{Co}_{9} \mathrm{~S}_{8} / \mathrm{Ni}$ and $\mathrm{MnS} / \mathrm{Ni}$. The CMS/Ni was designed as an efficient electrolyzer for overall water splitting.

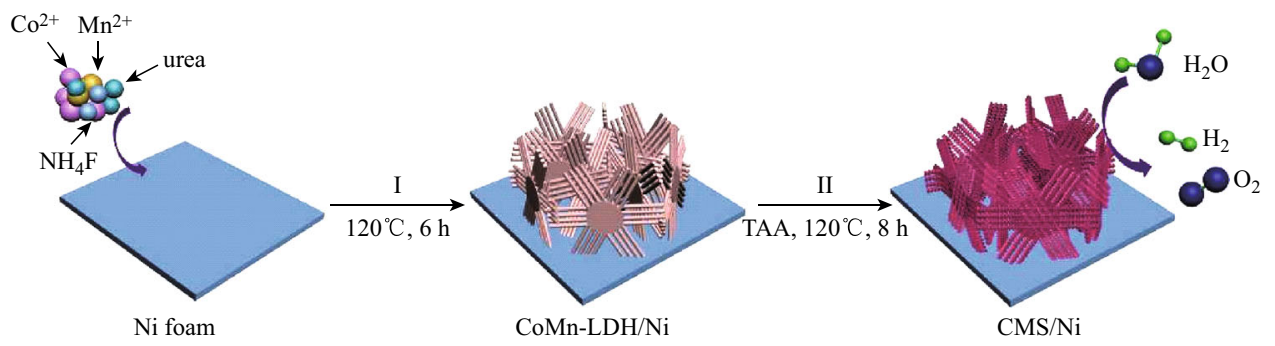

Scheme 1 Scheme of the synthesis procedure for CMS/Ni 


\section{Experimental Sections}

\subsection{Materials}

$\mathrm{MnCl}_{2} \cdot 4 \mathrm{H}_{2} \mathrm{O}, \mathrm{Co}\left(\mathrm{NO}_{3}\right)_{2} \cdot 6 \mathrm{H}_{2} \mathrm{O}$, urea and $\mathrm{NH}_{4} \mathrm{~F}$ were purchased from Aladdin. Ni foam was purchased from Kunshan Electronic Limited Corporation. All chemicals were directly used without any purification.

\subsection{Synthesis of CoMn-LDH/Ni}

Typically, $198 \mathrm{mg} \mathrm{MnCl}_{2} \cdot 4 \mathrm{H}_{2} \mathrm{O}, 582 \mathrm{mg} \mathrm{Co}\left(\mathrm{NO}_{3}\right)_{2} \cdot 6 \mathrm{H}_{2} \mathrm{O}$, $180 \mathrm{mg}$ urea and $37 \mathrm{mg} \mathrm{NH}_{4} \mathrm{~F}$ were dissolved into a beaker containing $40 \mathrm{~mL}$ distilled water and $10 \mathrm{~mL}$ absolute ethanol to form a homogeneous solution under stirring for 10 min. A piece of $\mathrm{Ni}$ foam $\left(3 \times 3 \mathrm{~cm}^{2}\right)$ which was cleaned by sonication sequentially in $3 \mathrm{~mol} \mathrm{~L}^{-1} \mathrm{HCl}$ solution and absolute ethanol for $15 \mathrm{~min}$ each was immersed into the above solution, and then, the mixture was transferred into an autoclave $(80 \mathrm{~mL})$. The autoclave was sealed and heated at $120{ }^{\circ} \mathrm{C}$ for $6 \mathrm{~h}$. After cooling down to room temperature, the precursor $\mathrm{CoMn}-\mathrm{LDH} / \mathrm{Ni}$ (XRD pattern is exhibited in Fig. S1) was taken out and washed by deionized water for four times and dried at $60{ }^{\circ} \mathrm{C}$.

\subsection{Synthesis of CMS/Ni}

To obtain the CMS/Ni, $400 \mathrm{mg}$ thioacetamide was dissolved in $50 \mathrm{~mL}$ deionized water. Then, the clean solution was transferred into an autoclave containing a piece of prepared CoMn-LDH/Ni. After heating at $120^{\circ} \mathrm{C}$ for $12 \mathrm{~h}$, the product was taken out and severally washed by absolute ethanol and deionized water for four times. Finally, the $\mathrm{CMS} / \mathrm{Ni}$ was obtained after dehydrating in an oven at $60{ }^{\circ} \mathrm{C}$ overnight. The mass loading of CMS is $4.1 \mathrm{mg} \mathrm{cm}^{-2}$. For comparison, the $\mathrm{Co}_{9} \mathrm{~S}_{8} / \mathrm{Ni}$ and $\mathrm{MnS} / \mathrm{Ni}$ were also synthesized through the same processes without adding the $\mathrm{Mn}^{2+}$ or $\mathrm{Co}^{2+}$ ions.

\subsection{Materials Characterization}

The X-ray diffraction (XRD) patterns were tested by a MSAL-XD2 X-ray diffractometer with $\mathrm{Cu} \mathrm{K} \alpha$ radiation ( $\lambda=1.5406 \AA$ ). The scanning electron microscopy (SEM) was performed by a Philips SEM-XL30S microscope operated at $15 \mathrm{kV}$. High-resolution transmission electron microscope (HRTEM, JEOL JEM-2100F) coupled with an energy-dispersive X-ray spectroscopy (EDS) analyzer was carried out with an accelerating voltage of $200 \mathrm{kV}$. The nitrogen sorption isotherms were carried out by a Micromeritics TriStar 3000 Analyzer at $77 \mathrm{~K}$. The X-ray photoelectron spectroscopy (XPS) was analyzed by an ESCALab250.

\subsection{Electrochemical Measurements}

All the electrochemical measurements were carried out in a conventional three-electrode system. The CMS/Ni and other obtained samples were used as the working electrodes. Pt foil and $\mathrm{Hg} / \mathrm{HgO}$ electrodes were separately used as the counter and reference electrodes. The $1.0 \mathrm{~mol} \mathrm{~L}^{-1}$ $\mathrm{KOH}$ was used as the electrolyte. Linear sweep voltammetry (LSV) was analyzed with a scan rate of $2 \mathrm{mV} \mathrm{s}^{-1}$. All potentials in this work were calibrated by the Nernst equation:

$E_{\mathrm{RHE}}=E_{\mathrm{Hg} / \mathrm{HgO}}+(0.098+0.059 \mathrm{pH}) \mathrm{V}$

$\eta=E_{\mathrm{RHE}}-1.23 \mathrm{~V}$

where $\eta$ is the overpotential. In addition, the Tafel slope was modeled by Tafel equation:

$\eta=b \log j+a$

where $\eta$ is the overpotential, $b$ is the Tafel slope, $j$ is the current density and $a$ is a constant. Chronoamperometry measurements were tested at a static potential, and the electrochemical impedance spectroscopy (EIS) was also performed in the frequency range from $10 \mathrm{kHz}$ to $10 \mathrm{mHz}$ with an amplitude of $5 \mathrm{mV}$. The electrochemically active surface areas (ECSAs) were evaluated by the electrochemical double-layer capacitance $\left(C_{\mathrm{dl}}\right)$ via collecting cyclic voltammograms (CVs). The different $\mathrm{CV}$ cycles $(5$, $10,15,20,30$, and $50 \mathrm{mV} \mathrm{s}^{-1}$ ) were tested in the nonFaradaic potential region from 0.124 to $0.224 \mathrm{~V} v$ s RHE to determine the $C_{\mathrm{dl}}$.

\section{Results and Discussion}

\subsection{Structure and Morphology of Materials}

The XRD patterns of the as-prepared samples were performed using their powders scraped down from the $\mathrm{Ni}$ foam. As shown in Fig. S2a, the XRD pattern of $\mathrm{Co}_{9} \mathrm{~S}_{8}$ exhibits the cubic crystalline phase with diffraction peaks at $29.8^{\circ}, 31.1^{\circ}, 47.6^{\circ}$, and $51.9^{\circ}$, which are severally corresponding to the (311), (222), (511), and (440) planes of $\mathrm{Co}_{9} \mathrm{~S}_{8}$ (No. 02-1459). Meanwhile, the typical diffraction peaks of MnS located at $34.3^{\circ}$ and $49.3^{\circ}$ are matched well with the (200) and (220) planes of cubic MnS (No. 65-2919). Interestingly, the XRD pattern of CMS reveals the crystal structures of the $\mathrm{Co}_{9} \mathrm{~S}_{8}$ and $\mathrm{MnS}$ are still maintained in CMS after modulating with them as a composite. Moreover, the EDS analysis reveals the atomic 
ratio of $\mathrm{Co}, \mathrm{Mn}$ and $\mathrm{S}$ is $\sim 0.9: 0.1: 1.0$ in the composite (Fig. S2b), while the $\mathrm{Cu}$ elemental is coming from copper mesh. Figure S2c, d shows the atomic ratios of $\mathrm{Co}_{9} \mathrm{~S}_{8}$ and MnS are 9.0:8.0 and 1.0:1.0, respectively.

Figure S3 presents the SEM images of $\mathrm{Co}_{9} \mathrm{~S}_{8} / \mathrm{Ni}$ and $\mathrm{MnS} / \mathrm{Ni}$. The nanosheet structures of $\mathrm{Co}_{9} \mathrm{~S}_{8} / \mathrm{Ni}$ and $\mathrm{MnS} / \mathrm{Ni}$ are still retained a rough surface with respect to their precursors. However, the morphologies are modified after combining with $\mathrm{Co}_{9} \mathrm{~S}_{8} / \mathrm{Ni}$ and $\mathrm{MnS} / \mathrm{Ni}$. It can be observed in Fig. 1a, b that the 3D hexagram-like CMS/Ni nanosheets were obtained after sulfonating the $\mathrm{CoMn}-\mathrm{LDH} / \mathrm{Ni}$ (Fig. S4), and each "hexagram" is entirely covered by uniform nanosheets (Fig. 1c). The TEM image shown in Fig. 1d reveals the 3D hexagram-like CMS/Ni nanosheets which are made up of solid nanorods. Figure 1e shows the HRTEM image, where the distinct lattice fringes of $d=0.300 \mathrm{~nm}$ and $d=0.191 \mathrm{~nm}$ are corresponding to (311) and (511) crystal plane of $\mathrm{Co}_{9} \mathrm{~S}_{8}$, respectively, and the $d=0.261 \mathrm{~nm}$ is attributed to (200) crystal plane of $\mathrm{MnS}$. This result indicates that the CMS is a composite material, which is comprised by the interrelated $\mathrm{Co}_{9} \mathrm{~S}_{8}$ and $\mathrm{MnS}$. Additionally, it can be seen that the elements of $\mathrm{Co}$, $\mathrm{Mn}$ and $\mathrm{S}$ are uniformly dispersed in $\mathrm{CMS} / \mathrm{Ni}$, as shown in Fig. 1f.

The Co 2p XPS spectra of CMS/Ni in Fig. 1g reveal two distinct peaks at 781.0 and $797.3 \mathrm{eV}$ corresponding to the Co $2 p_{3 / 2}$ and Co $2 p_{1 / 2}$, respectively, with two related satellite peaks at 786.3 and $802.9 \mathrm{eV}$. These are the characteristic peaks of $\mathrm{Co}^{2+}$ [50], and the other two peaks at 778.2 and $793.2 \mathrm{eV}$ are assigned to the metallic Co [50]. Nevertheless, there is not metallic Co presented on the Co $2 p$ XPS spectra of $\mathrm{Co}_{9} \mathrm{~S}_{8} / \mathrm{Ni}$ counterpart (Fig. S5a). Moreover, there are no diffraction peaks of metallic Co presenting in the XRD pattern of $\mathrm{CMS} / \mathrm{Ni}$, which may be attributed to its low content in CMS/Ni. As Mn $2 p$ XPS spectra of CMS/Ni shown in Fig. 1h, the peak located at
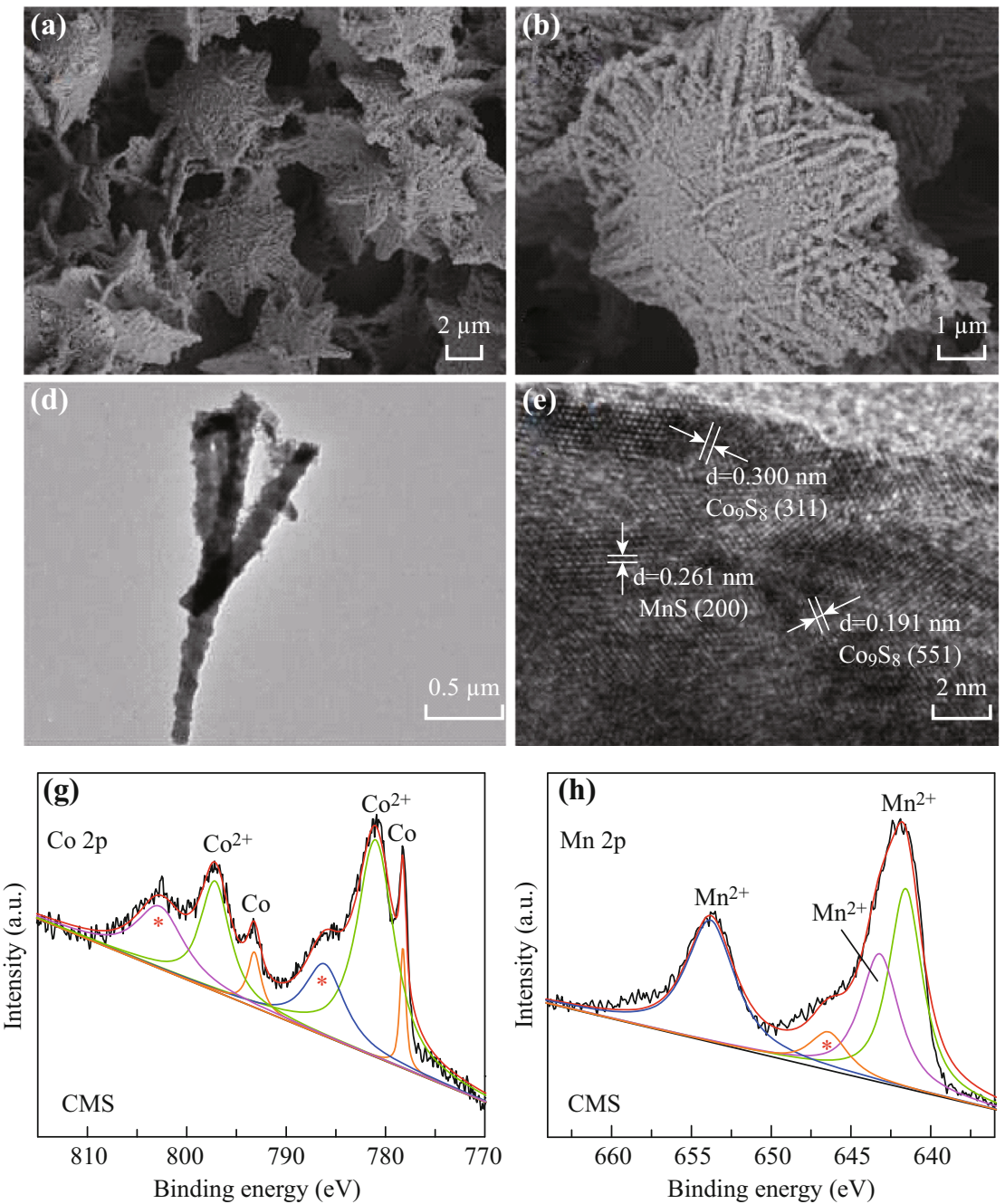
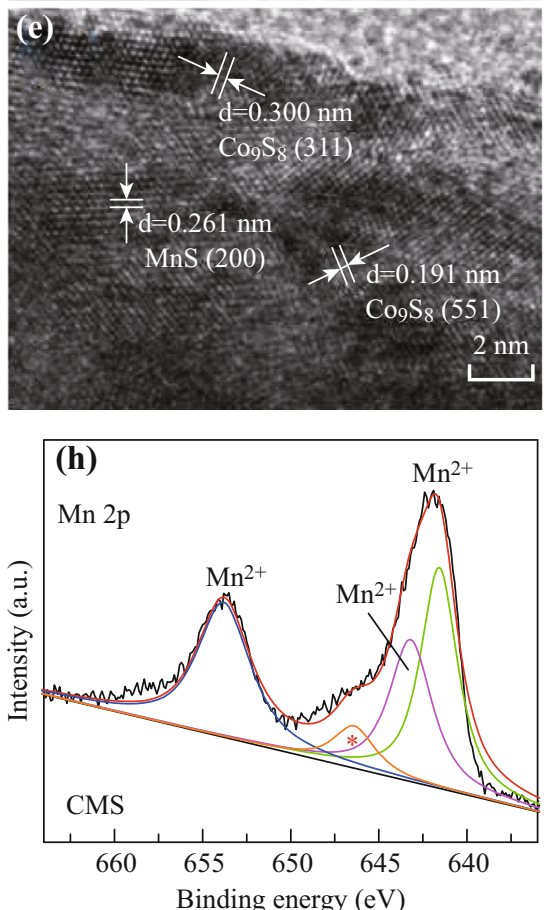
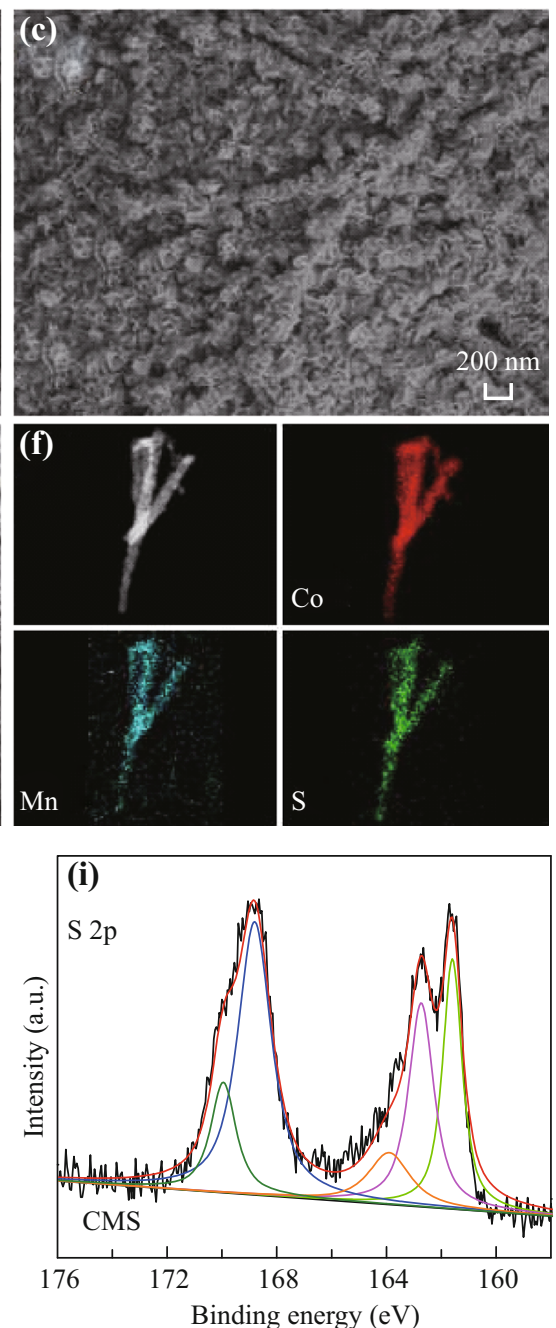

Fig. 1 The characterization results of CMS/Ni: a-c SEM images in different magnifications, $\mathbf{d}$ TEM image, e HRTEM image, $\mathbf{f}$ elemental mapping images and $\mathbf{g}-\mathbf{i}$ XPS spectra 
$643.3 \mathrm{eV}$ confirms the oxidized $\mathrm{Mn}^{3+}$ species in $\mathrm{CMS} / \mathrm{Ni}$ $[50,55]$, while there is no $\mathrm{Mn}^{3+}$ detected from XPS spectra of $\mathrm{MnS} / \mathrm{Ni}$ counterpart (Fig. S5b). Simultaneously, $\mathrm{Mn}^{2+}$ reveals with two characteristic peaks at bending energies of $641.6 \mathrm{eV}\left(\mathrm{Mn} 2 p_{3 / 2}\right)$ and $653.8 \mathrm{eV}\left(\mathrm{Mn} \mathrm{2} p_{1 / 2}\right)$. The above results are similar to Yang's work [50]. The occurrence of metallic Co and $\mathrm{Mn}^{3+}$ in CMS/Ni can be explained by the higher reduction potential of $\mathrm{Co}^{2+} / \mathrm{Co}\left(\mathrm{Co}^{2+}+2 \mathrm{e}^{-} \rightarrow \mathrm{Co}\right.$, $-0.277 \mathrm{~V}$ vs. NHE) comparing to $\mathrm{Mn}^{2+} / \mathrm{Mn}$ $\left(\mathrm{Mn}^{2+}+2 \mathrm{e}^{-} \rightarrow \mathrm{Mn},-1.18 \mathrm{~V}\right.$ vs. NHE). This means that the $\mathrm{Co}^{2+}$ as oxidizer is easier to be reduced from $\mathrm{Co}^{2+}$ to metallic Co than the same reaction of $\mathrm{Mn}^{2+}$. The reduction in $\mathrm{Co}^{2+}$ to metallic Co would result in the oxidation of $\mathrm{Mn}^{2+}$ to $\mathrm{Mn}^{3+}$ at the same time $\left(\mathrm{Mn}^{2+}-\right.$ $\mathrm{e}^{-} \rightarrow \mathrm{Mn}^{3+}, 1.5 \mathrm{~V}$ vs. NHE) [56]. The different valance states of metal cations in $\mathrm{CMS} / \mathrm{Ni}$ are benefit for improving the catalytic performance $[42,50]$. Figure $1 \mathrm{i}$ shows the peaks of $\mathrm{S} 2 p_{3 / 2}$ and $\mathrm{S} 2 p_{1 / 2}$ are located at 161.6 and $162.7 \mathrm{eV}$, respectively, which are derived from metalsulfur bonds [50]. Furthermore, a peak at $168.8 \mathrm{eV}$ with its satellite peak at $170.0 \mathrm{eV}$ is attributed to the superficial oxidation of $\mathrm{CMS} / \mathrm{Ni}$ in air [55].

\subsection{Hydrogen Evolution Activity}

The electrocatalytic activity of CMS/Ni toward HER was characterized by LSV measurement with a scan rate of $2 \mathrm{mV} \mathrm{s}^{-1}$. For comparison, the $\mathrm{Co}_{9} \mathrm{~S}_{8} / \mathrm{Ni}, \mathrm{MnS} / \mathrm{Ni}$, bare $\mathrm{Ni}$ foam and commercial $50 \mathrm{wt} \% \mathrm{Pt} / \mathrm{C}$ coated on Ni foam $(50$ wt\% Pt/C/Ni [30], loading $4.1 \mathrm{mg} \mathrm{cm}^{-2}$ ) were also evaluated. As the polarization curves illustrated in Fig. 2a, the $50 \mathrm{wt} \% \mathrm{Pt} / \mathrm{C} / \mathrm{Ni}$ possesses the most excellent HER performance with a near-zero onset potential. The CMS/Ni reveals a much smaller onset potential at $-88 \mathrm{mV}$ and larger HER current than those of $\mathrm{Co}_{9} \mathrm{~S}_{8} / \mathrm{Ni}, \mathrm{MnS} / \mathrm{Ni}$ and bare $\mathrm{Ni}$ foam. This result highlights the catalytic activity of CMS/Ni has significantly enhanced after combining $\mathrm{Co}_{9} \mathrm{~S}_{8} /$ $\mathrm{Ni}$ with $\mathrm{MnS} / \mathrm{Ni}$ as a composite, which may be ascribed to the synergistic effect of $\mathrm{Co}$ and $\mathrm{Mn}$. The HER performance of CMS/Ni is also comparable with the CoMn-LDH/Ni, as
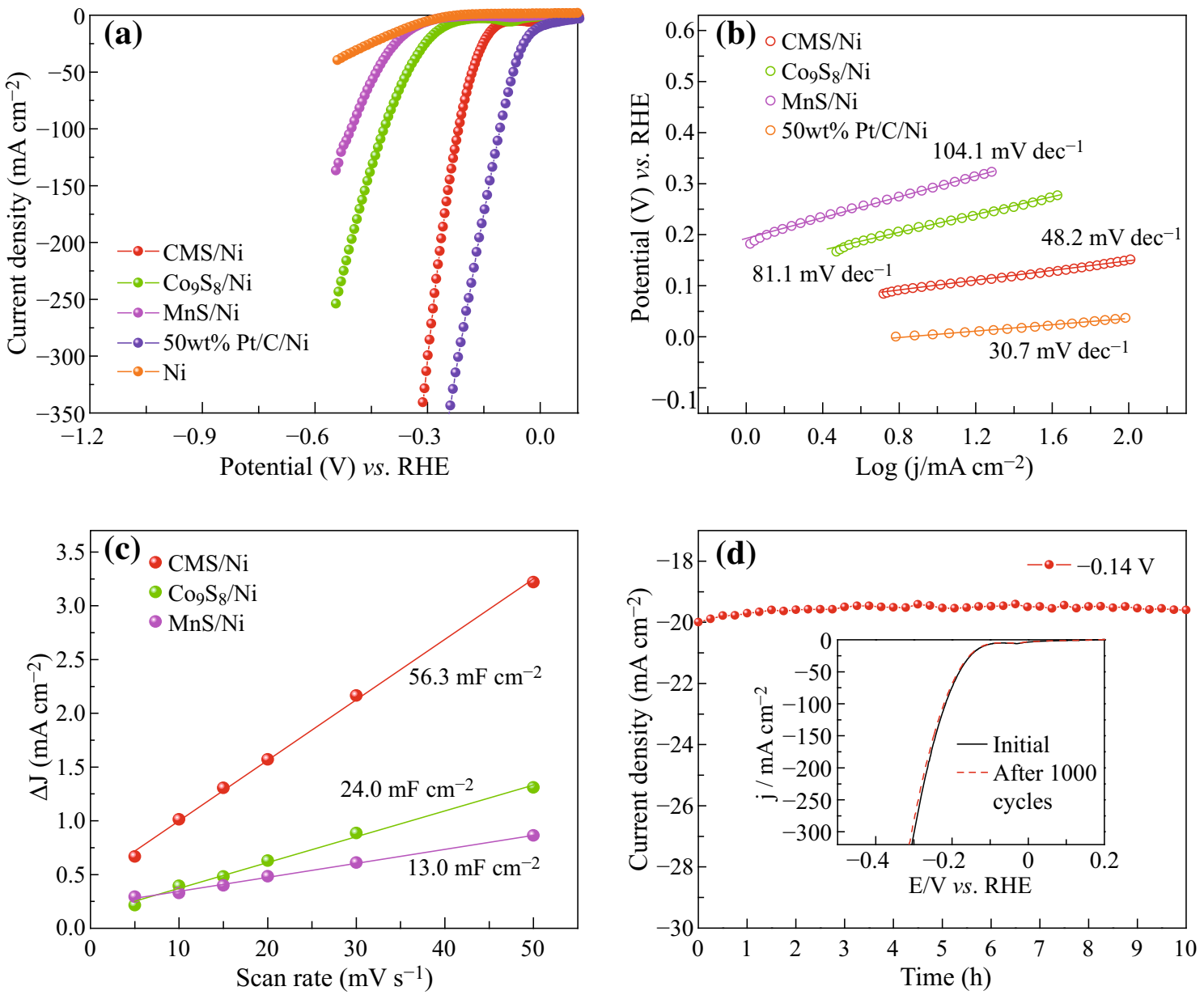

Fig. 2 a Polarization curves, b Tafel plots, $\mathbf{c}$ plots of the current density for $\mathrm{CMS} / \mathrm{Ni}, \mathrm{Co}_{9} \mathrm{~S}_{8} / \mathrm{Ni}, \mathrm{MnS} / \mathrm{Ni}$ at potential of $0.174 \mathrm{~V}$ against the scan rates and $\mathbf{d}$ chronoamperometric curve (the inset is polarization curves before and after $1000 \mathrm{CV}$ cycles) 
shown in Fig. S6a, b. Noticeably, the CMS/Ni drives a high current density of $100 \mathrm{~mA} \mathrm{~cm}^{-2}$ at an overpotential of $217 \mathrm{mV}$, which is lower than $419 \mathrm{mV}$ for $\mathrm{Co}_{9} \mathrm{~S}_{8} / \mathrm{Ni}$ and $506 \mathrm{mV}$ for $\mathrm{MnS} / \mathrm{Ni}$. Such an overpotential of CMS/Ni is superior to most of the recently reported bifunctional electrocatalysts listed in Table S1. The efficient catalytic activity of CMS/Ni is also supported by the Tafel slopes in Fig. 2b. The Tafel slope of CMS/Ni is $48.2 \mathrm{mV} \mathrm{dec}^{-1}$ which is obviously lower than $81.1 \mathrm{mV} \mathrm{dec}^{-1}$ for $\mathrm{Co}_{9} \mathrm{~S}_{8} / \mathrm{Ni}$ and $104.1 \mathrm{mV} \mathrm{dec}^{-1}$ for $\mathrm{MnS} / \mathrm{Ni}$, implying great HER kinetics and catalytic activity. In addition, the EIS measurements of $\mathrm{CMS} / \mathrm{Ni}, \mathrm{Co}_{9} \mathrm{~S}_{8} / \mathrm{Ni}$ and $\mathrm{MnS} / \mathrm{Ni}$ were measured at a static potential of $-0.33 \mathrm{~V}$ to further elucidate the charge transport of the as-prepared materials. As exhibited in Fig. S7, the CMS/Ni shows lower resistance of $0.98 \Omega$ than the pure $\mathrm{Co}_{9} \mathrm{~S}_{8} / \mathrm{Ni}(1.80 \Omega)$ and $\mathrm{MnS} / \mathrm{Ni}(2.14$ $\Omega)$, suggesting an improvement of conductivity. The lower charge-transfer resistance of CMS/Ni may be attributed to its uniquely 3D hexagram-like nanosheets structure contacting with the electrolyte efficiently, and the metallic Co generated in CMS (see Fig. 1g) after integrating with two $\mathrm{Co}_{9} \mathrm{~S}_{8}$ and $\mathrm{MnS}$ to be the composite [50].

On the other hand, the superior activity of $\mathrm{CMS} / \mathrm{Ni}$ for $\mathrm{HER}$, in comparison with that of the pure $\mathrm{Co}_{9} \mathrm{~S}_{8} / \mathrm{Ni}$ and $\mathrm{MnS} / \mathrm{Ni}$, results from the significant increase in electrochemical active surface areas (ECSAs) to expose more accessible catalytic active sites. The ECSAs of CMS/Ni, $\mathrm{Co}_{9} \mathrm{~S}_{8} / \mathrm{Ni}$ and $\mathrm{MnS} / \mathrm{Ni}$ were measured by the capacitance measurements through cyclic voltammograms in a nonFaradaic at different scan rates (Fig. S8). The ECSA of an electrocatalyst is proportional to its $C_{\mathrm{dl}}$ value. It can be seen that the $C_{\mathrm{dl}}$ values of $24.0 \mathrm{mF} \mathrm{cm}^{-2}$ for $\mathrm{Co}_{9} \mathrm{~S}_{8} / \mathrm{Ni}$ and $13.0 \mathrm{mF} \mathrm{cm}^{-2}$ for $\mathrm{MnS} / \mathrm{Ni}$ are tremendously increase to $56.3 \mathrm{mF} \mathrm{cm}^{-2}$ for $\mathrm{CMS} / \mathrm{Ni}$, implying the CMS/Ni has more effective active sites, as shown in Fig. 2c.

The HER stability of CMS/Ni was further evaluated at a constant potential of $-0.14 \mathrm{~V}$. As shown in Fig. $2 \mathrm{~d}$, the $\mathrm{CMS} / \mathrm{Ni}$ reveals a great stability with a negligible decay of the current density after $10 \mathrm{~h}$ continuous measurements. Simultaneously, the LSV polarization curve tested at $100 \mathrm{mV} \mathrm{s}^{-1}$ after 1000 cycles is similar to the first cycle, as the inset in Fig. 2d. The superior durability of CMS/Ni is benefit from its high structure stability because the hexagram-like structure for CMS/Ni just exhibits a little aggregation after stability measurement in Fig. S9a. The excellent catalytic performance and great stability highlight the great potential of $\mathrm{CMS} / \mathrm{Ni}$ for practical application.

\subsection{Oxygen Evolution Activity}

The electrocatalytic activity of CMS/Ni for OER was also characterized by LSV measurement with a scan rate of $2 \mathrm{mV} \mathrm{s}^{-1}$. The $\mathrm{Co}_{9} \mathrm{~S}_{8} / \mathrm{Ni}, \mathrm{MnS} / \mathrm{Ni}$, bare $\mathrm{Ni}$ foam and commercial $\mathrm{RuO}_{2}$ coated on $\mathrm{Ni}$ foam $\left(\mathrm{RuO}_{2} / \mathrm{Ni}\right.$ [30], loading $4.1 \mathrm{mg} \mathrm{cm}^{-2}$ ) were evaluated for comparison. Figure $3 \mathrm{a}$ shows the polarization curves of the as-prepared samples, in which the oxidation peaks from 1.33 to $1.41 \mathrm{~V}$ are ascribed to the transition from $\mathrm{M}^{2+}$ to $\mathrm{M}^{3+}$ [30]. Owing to the intense oxidation peaks, the overpotential for materials to generate the anodic current of $10 \mathrm{~mA} \mathrm{~cm}^{-2}$ for OER is not accurate. Therefore, we report the overpotentials at $100 \mathrm{~mA} \mathrm{~cm}^{-2}$ here. As observed, a current density of $100 \mathrm{~mA} \mathrm{~cm}{ }^{-2}$ is easily reached at the overpotential of $298 \mathrm{mV}$ for $\mathrm{CMS} / \mathrm{Ni}$, better than those of $\mathrm{Co}_{9} \mathrm{~S}_{8} / \mathrm{Ni}$ (439 mV), MnS/Ni (492 mV), $\mathrm{RuO}_{2} / \mathrm{Ni}(568 \mathrm{mV}$ ) and even most of the other recently reported bifunctional materials exhibited in Table S1. The above results suggest the efficient OER activity of $\mathrm{CMS} / \mathrm{Ni}$, which is also superior to the CoMn-LDH/Ni (Fig. S6c, d). A tremendous improvement of catalytic performance for $\mathrm{CMS} / \mathrm{Ni}$ with respect to its monometallic counterparts can also be supported by its smallest Tafel slope. As shown in Fig. 3b, the smallest Tafel slopes of $43.9 \mathrm{mV} \mathrm{dec}^{-1}$ for CMS/Ni with respect to $\mathrm{Co}_{9} \mathrm{~S}_{8} / \mathrm{Ni} \quad\left(71.5 \mathrm{mV} \mathrm{dec}{ }^{-1}\right), \quad \mathrm{MnS} / \mathrm{Ni}$ (100.3 $\left.\mathrm{mV} \mathrm{dec}^{-1}\right)$ and $\mathrm{RuO}_{2} / \mathrm{Ni}\left(132.4 \mathrm{mV} \mathrm{dec}^{-1}\right)$ imply the great OER kinetics activity.

The stability of CMS/Ni for OER was calculated at a static potential of $1.46 \mathrm{~V}$ in $1.0 \mathrm{~mol} \mathrm{~L}^{-1} \mathrm{KOH}$ solution. Figure $3 \mathrm{c}$ presents a negligible decrease in current density after $10 \mathrm{~h}$ continuing OER measurement, indicating the superior durability. Additionally, this result can be further confirmed by the LSV curves in Fig. 3d, because the polarization curve after 1000 cycles is similar to the initial cycle. In particular, it can be seen that the morphology of CMS/Ni slightly changes after stability testing in Fig. S9b.

All the above results indicate that the CMS/Ni possesses superior HER and OER catalytic activity comparing to the pure $\mathrm{Co}_{9} \mathrm{~S}_{8} / \mathrm{Ni}$ and $\mathrm{MnS} / \mathrm{Ni}$, which could be involved the following factors: (1) The obtained CMS/Ni has a uniquely 3D hexagram-like nanosheet structure, which not only provides a large electrochemical active surface areas (ECSAs) to expose more accessible catalytic active sites, but also contacts with the electrolyte efficiently and facilitates the transportation of $\mathrm{O}_{2}, \mathrm{H}_{2}$ bubbles [28, 32, 57]; (2) the 3D hexagram-like CMS directly supported on $\mathrm{Ni}$ foam substrate enhances the structure stability and improves electrons transport ability of $\mathrm{CMS} / \mathrm{Ni}$, which are beneficial to improving the catalytic activity; and (3) the XPS results (shown in Fig. 1g, h) indicate that the different valence states of $\mathrm{Co}$ and $\mathrm{Mn}$ are presented in the $\mathrm{CMS} / \mathrm{Ni}$, which can facilitate the adsorption and desorption of intermediates in the electrocatalysis process. The synergistic effect between $\mathrm{Co}$ and $\mathrm{Mn}$ is helpful for the catalytic activity [42, 49, 50, 58]. 

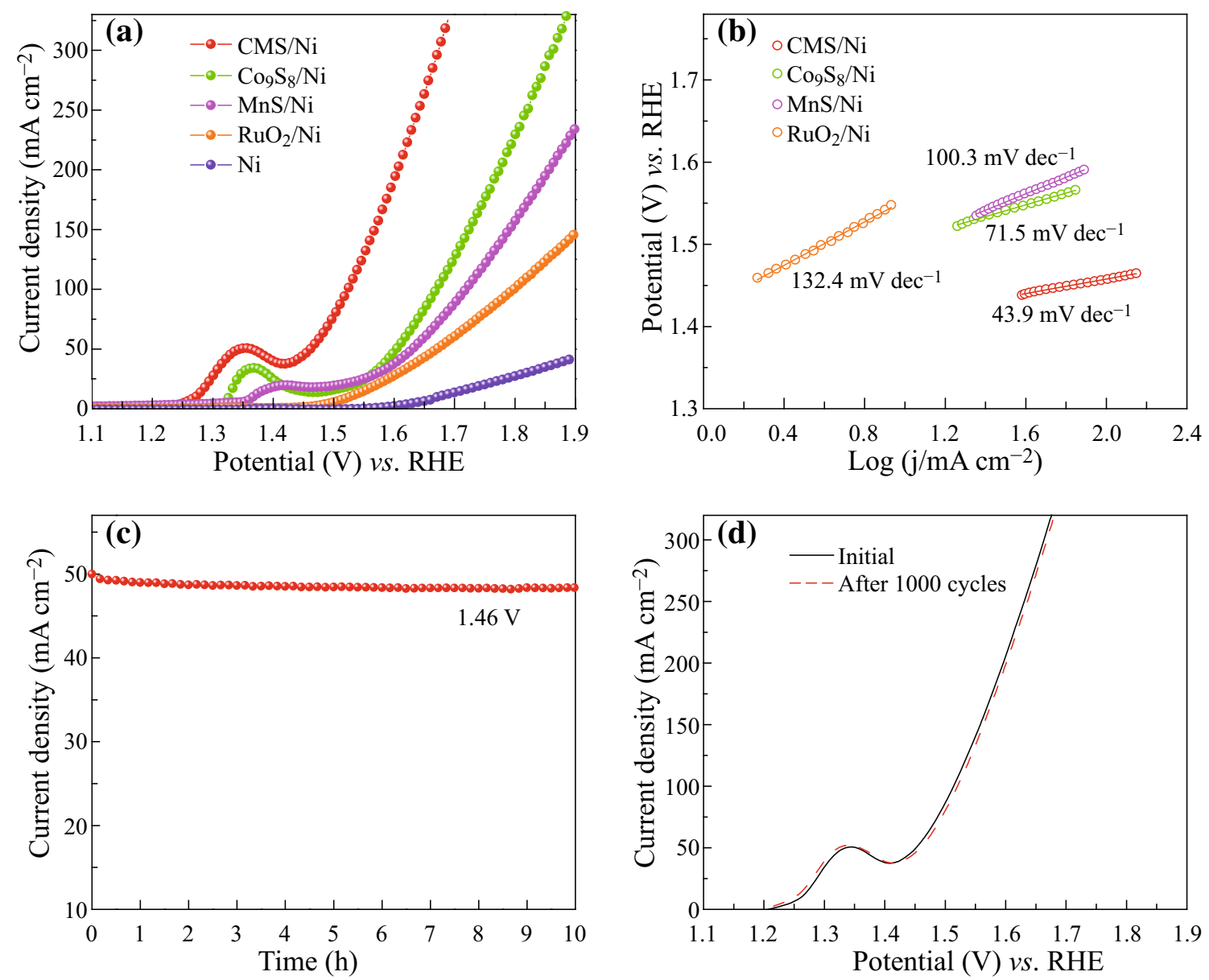

Fig. 3 a Polarization curves, b Tafel plots, c chronoamperometric curve and d polarization curves before and after $1000 \mathrm{CV}$ cycles

\subsection{Overall Water Splitting}

Based on the excellent activity toward OER and HER, the $\mathrm{CMS} / \mathrm{Ni}$ was directly assembled as the cathodic and anodic electrodes in two-electrode cell $(\mathrm{CMS} / \mathrm{Ni} / / \mathrm{CMS} / \mathrm{Ni})$ in $1.0 \mathrm{~mol} \mathrm{~L}^{-1} \mathrm{KOH}$ electrolyte for overall water splitting. As shown in Fig. 4a, the LSV curve of the cell indicates that water is electrolyzed only at the voltage of $1.47 \mathrm{~V}$ to
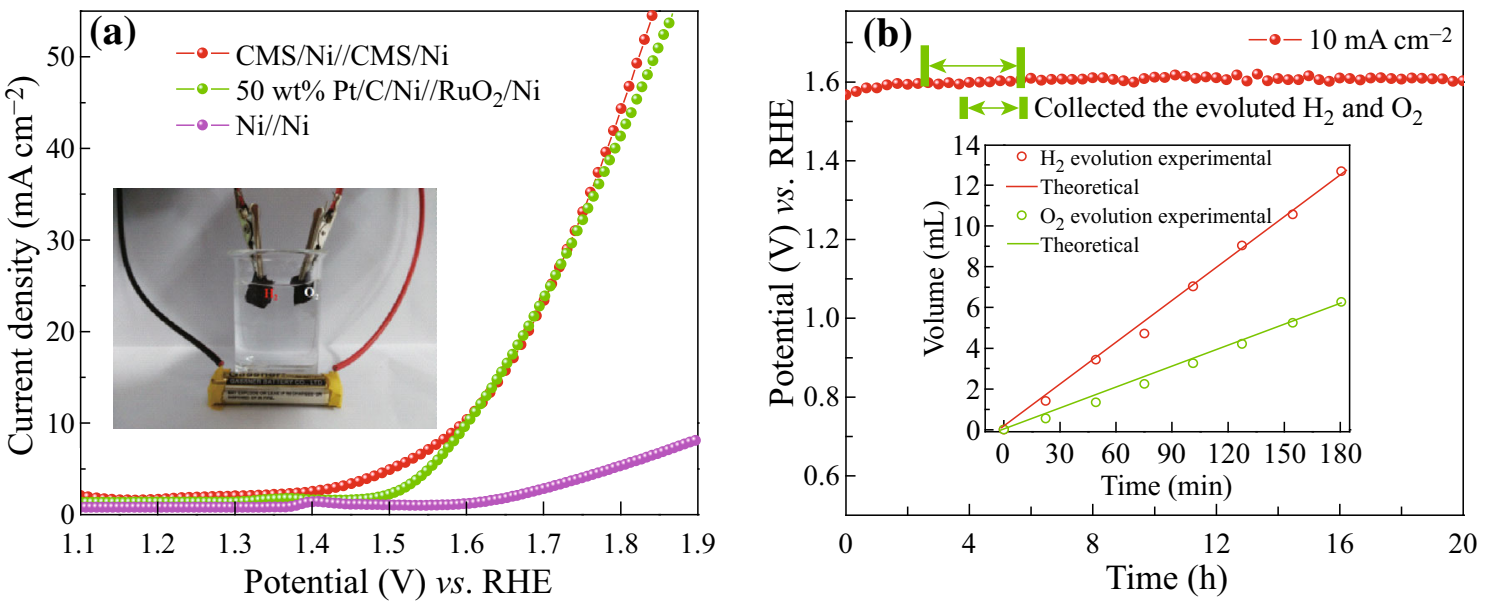

Fig. 4 a Polarization curves of $\mathrm{CMS} / \mathrm{Ni} / / \mathrm{CMS} / \mathrm{Ni}, 50 \mathrm{wt} \mathrm{Pt} / \mathrm{C} / \mathrm{Ni} / / \mathrm{RuO}_{2} / \mathrm{Ni}$ and $\mathrm{Ni} / / \mathrm{Ni}$ for overall water splitting (the inset is a device for overall water splitting). b Chronopotentiometry curve of CMS/Ni//CMS/Ni (the inset is volume of $\mathrm{O}_{2}$ and $\mathrm{H}_{2}$ generated for theoretically calculated and experimentally measured versus time) 
generate $\mathrm{H}_{2}$ and $\mathrm{O}_{2}$ bubbles. This result is supported by a device, which is driven by a $1.50 \mathrm{~V}$ dry battery (the inset in Figs. 4a and S10). For comparison, the $50 \mathrm{wt} \% \mathrm{Pt} / \mathrm{C} / \mathrm{Ni}$, $\mathrm{RuO}_{2} / \mathrm{Ni}$ and bare $\mathrm{Ni}$ foam were also used as the twoelectrode electrolyzers. A current density of $10 \mathrm{~mA} \mathrm{~cm}{ }^{-2}$ for $\mathrm{CMS} / \mathrm{Ni} / / \mathrm{CMS} / \mathrm{Ni}$ can be achieved at a cell voltage of $1.60 \mathrm{~V}$, equaling to that of $1.60 \mathrm{~V}$ for $50 \mathrm{wt} \% \mathrm{Pt} / \mathrm{C} / \mathrm{Ni} / /$ $\mathrm{RuO}_{2} / \mathrm{Ni}$. Although this cell voltage $(1.60 \mathrm{~V})$ of $\mathrm{CMS} / \mathrm{Ni} / /$ $\mathrm{CMS} / \mathrm{Ni}$ is higher than $1.52 \mathrm{~V}$ for $\mathrm{Cu} @ \mathrm{CoS}_{x} / \mathrm{CF}-$ $\mathrm{Cu} @ \mathrm{CoS}_{x} / \mathrm{CF}$ [59], $1.45 \mathrm{~V}$ for $\mathrm{MoO}_{x} / \mathrm{Ni}_{3} \mathrm{~S}_{2} / \mathrm{NF} / / \mathrm{MoO}_{x} /$ $\mathrm{Ni}_{3} \mathrm{~S}_{2} / \mathrm{NF}[60]$ and $1.53 \mathrm{~V}$ for $\mathrm{NixCo}_{3-x} \mathrm{~S}_{4} / \mathrm{Ni}_{3} \mathrm{~S}_{2} / \mathrm{NF} / / \mathrm{Ni}_{x-}$ $\mathrm{Co}_{3-x} \mathrm{~S}_{4} / \mathrm{Ni}_{3} \mathrm{~S}_{2} / \mathrm{NF}$ [61], it is superior to that of $\mathrm{NiCo}_{2} \mathrm{~S}_{4}$ $\mathrm{NW} / \mathrm{NF} / \mathrm{NiCo}_{2} \mathrm{~S}_{4} \mathrm{NW} / \mathrm{NF}(1.68 \mathrm{~V})$ [25], $\mathrm{FeNi}_{3} \mathrm{~N} / \mathrm{NF} / /$ $\mathrm{FeNi}_{3} \mathrm{~N} / \mathrm{NF}(1.62 \mathrm{~V})$ [27], Ni/NiP//Ni/NiP (1.61 V) [30], $\mathrm{Co}_{3} \mathrm{O}_{4} @ \mathrm{Ni} / / \mathrm{Co}_{3} \mathrm{O}_{4} @ \mathrm{Ni}$ (1.64 V) [32], $\mathrm{Ni}_{2.5} \mathrm{Co}_{0.5} \mathrm{Fe} / \mathrm{NF} / /$ $\mathrm{Ni}_{2.5} \mathrm{Co}_{0.5} \mathrm{Fe} / \mathrm{NF}(1.62 \mathrm{~V})$ [35], $\mathrm{Ni}(\mathrm{OH})_{2} / \mathrm{NF} / \mathrm{Ni}(\mathrm{OH})_{2} / \mathrm{NF}$ $(1.68 \mathrm{~V})$ [36], $\mathrm{Co}_{1} \mathrm{Mn}_{1} \mathrm{CH} / \mathrm{NF} / / \mathrm{Co}_{1} \mathrm{Mn}_{1} \mathrm{CH} / \mathrm{NF}(1.68 \mathrm{~V})$ [41], $\mathrm{Co}\left(\mathrm{S}_{0.71} \mathrm{Se}_{0.29}\right)_{2} / / \mathrm{Co}\left(\mathrm{S}_{0.22} \mathrm{Se}_{0.78}\right)_{2}$ (1.63 V) [43] and the two-electrode electrolyzers listed in Table S1. In addition, the chronopotentiometry curve of CMS/Ni//CMS/ $\mathrm{Ni}$ was measured at a constant current of $10 \mathrm{~mA} \mathrm{~cm}{ }^{-2}$ for $20 \mathrm{~h}$, exhibiting a great stability for $\mathrm{CMS} / \mathrm{Ni} / / \mathrm{CMS} / \mathrm{Ni}$ in Fig. 4b. The volume-time plots for generating $\mathrm{O}_{2}$ and $\mathrm{H}_{2}$ suggest that the Faradaic efficiency of $\mathrm{CMS} / \mathrm{Ni} / / \mathrm{CMS} / \mathrm{Ni}$ electrolyzer is nearly $100 \%$ (see the inset in Fig. 4b and experimental details are shown in SI).

\section{Conclusions}

In summary, a simple anion exchange method was employed to successfully prepare 3D hexagram-like CMS/ Ni. The 3D hexagram-like CMS/Ni nanosheets have large electrochemical active surface area to expose more active sites and low charge-transfer resistance. Noticeably, the synergetic effect of $\mathrm{Co}$ and $\mathrm{Mn}$ is also presented in this composite. Consequently, it exhibits superior catalytic activity in basic medium with low overpotentials of $217 \mathrm{mV}$ for HER and $298 \mathrm{mV}$ for OER to reach a current density of $100 \mathrm{~mA} \mathrm{~cm}{ }^{-2}$. More importantly, the assembled $\mathrm{CMS} / \mathrm{Ni} / / \mathrm{CMS} / \mathrm{Ni}$ device for overall water splitting can be driven by a $1.50 \mathrm{~V}$ dry battery, indicating the great potential for practical applications. Therefore, this work provides a scalable method to synthesize bi- or multimetallic sulfide composites and extends the preparation of the other novel electrocatalysts for water splitting.

Acknowledgements This work was supported by National Natural Science Foundation of China (21576113 and 21376105) and Foshan Innovative and Entrepreneurial Research Team Program (No. 2014IT100062)

Open Access This article is distributed under the terms of the Creative Commons Attribution 4.0 International License (http:// creativecommons.org/licenses/by/4.0/), which permits unrestricted use, distribution, and reproduction in any medium, provided you give appropriate credit to the original author(s) and the source, provide a link to the Creative Commons license, and indicate if changes were made.

\section{References}

1. C.G. Morales-Guio, M.T. Mayer, A. Yella, S.D. Tilley, M. Gratzel, X. Hu, An optically transparent iron nickel oxide catalyst for solar water splitting. J. Am. Chem. Soc. 137(31), 9927-9936 (2015). doi:10.1021/jacs.5b05544

2. M.G. Walter, E.L. Warren, J.R. McKone, S.W. Boettcher, Q. Mi, E.A. Santori, N.S. Lewis, Solar water splitting cells. Chem. Rev. 110(11), 6446-6473 (2010). doi:10.1021/cr1002326

3. L. Kuai, J. Geng, C. Chen, E. Kan, Y. Liu, Q. Wang, B. Geng, A reliable aerosol-spray-assisted approach to produce and optimize amorphous metal oxide catalysts for electrochemical water splitting. Angew. Chem. Int. Ed. 126(29), 7677-7681 (2014). doi:10.1002/anie. 201404208

4. J. Suntivich, K.J. May, H.A. Gasteiger, J.B. Goodenough, Y. Shao-Horn, A perovskite oxide optimized for oxygen evolution catalysis from molecular orbital principles. Science 334(6061), 1383-1385 (2011). doi:10.1126/science. 1212858

5. B. Rausch, M.D. Symes, G. Chisholm, L. Cronin, Decoupled catalytic hydrogen evolution from a molecular metal oxide redox mediator in water splitting. Science 345(6202), 1326-1330 (2014). doi:10.1126/science.1257443

6. J.W.D. Ng, M. García-Melchor, M. Bajdich, P. Chakthranont, C. Kirk, A. Vojvodic, T.F. Jaramillo, Gold-supported cerium-doped $\mathrm{NiO}_{x}$ catalysts for water oxidation. Nat. Energy 1(5), 16053 (2016). doi:10.1038/nenergy.2016.53

7. Y. Gorlin, T.F. Jaramillo, A bifunctional nonprecious metal catalyst for oxygen reduction and water oxidation. J. Am. Chem. Soc. 132(39), 13612-13614 (2010). doi:10.1021/ja104587v

8. X. Zhang, C. Si, X. Guo, R. Konga, F. Qu, $\mathrm{MnCo}_{2} \mathrm{~S}_{4}$ nanowire array as an earth-abundant electrocatalyst for efficient oxygen evolution reaction under alkaline conditions. J. Mater. Chem. A 5(33), 17211-17215 (2017). doi:10.1039/C7TA04804A

9. J. Zhang, Y. Hu, D. Liu, Y. Yu, B. Zhang, Enhancing oxygen evolution reaction at high current densities on amorphous-like $\mathrm{Ni}-\mathrm{Fe}-\mathrm{S}$ ultrathin nanosheets via oxygen incorporation and electrochemical tuning. Adv. Sci. 4(3), 1600343 (2017). doi:10. 1002/advs.201600343

10. D. Yang, L. Gao, J.-H. Yang, Facile synthesis of ultrathin $\mathrm{Ni}(\mathrm{OH})_{2}-\mathrm{Cu}_{2} \mathrm{~S}$ hexagonal nanosheets hybrid for oxygen evolution reaction. J. Power Sources 359, 52-56 (2017). doi:10.1016/j. jpowsour.2017.05.034

11. J. Long, Y. Gong, J. Lin, Metal-organic framework-derived $\mathrm{Co}_{9} \mathrm{~S}_{8} @ \mathrm{CoS} @ \mathrm{CoO} @ \mathrm{C}$ nanoparticles as efficient electro- and photo-catalysts for the oxygen evolution reaction. J. Mater. Chem. A 5(21), 10495-10509 (2017). doi:10.1039/C7TA01447C

12. B.Y. Guan, L. Yu, X.W. Lou, General synthesis of multishell mixed-metal oxyphosphide particles with enhanced electrocatalytic activity in the oxygen evolution reaction. Angew. Chem. Int. Ed. 56(9), 2386-2389 (2017). doi:10.1002/anie.201611804

13. N.T. Suen, S.F. Hung, Q. Quan, N. Zhang, Y.J. Xu, H.M. Chen, Electrocatalysis for the oxygen evolution reaction: recent development and future perspectives. Chem. Soc. Rev. 46(2), 337-365 (2017). doi:10.1039/C6CS00328A

14. X. Chen, Z. Zhang, L. Chi, A.K. Nair, W. Shangguan, Z. Jiang, Recent advances in visible-light-driven photoelectrochemical water splitting: catalyst nanostructures and reaction systems. 
Nano-Micro Lett. 8(1), 1-12 (2015). doi:10.1007/s40820-0150063-3

15. R. Li, L. Yang, T. Xiong, Y. Wu, L. Cao, D. Yuan, W. Zhou, Nitrogen doped $\mathrm{MoS}_{2}$ nanosheets synthesized via a low-temperature process as electrocatalysts with enhanced activity for hydrogen evolution reaction. J. Power Sources 356, 133-139 (2017). doi:10.1016/j.jpowsour.2017.04.060

16. C. Wang, B. Tian, M. Wu, J. Wang, Revelation of the excellent intrinsic activity of $\mathrm{MoS}_{2}|\mathrm{NiS}| \mathrm{MoO}_{3}$ nanowires for hydrogen evolution reaction in alkaline medium. ACS Appl. Mater. Interfaces 9(8), 7084-7090 (2017). doi:10.1021/acsami.6b14827

17. Z. Wu, J. Guo, J. Wang, R. Liu, W. Xiao, C. Xuan, K. Xia, D. Wang, Hierarchically porous electrocatalyst with vertically aligned defect-rich CoMoS nanosheets for the hydrogen evolution reaction in an alkaline medium. ACS Appl. Mater. Interfaces 9(6), 5288-5294 (2017). doi:10.1021/acsami.6b15244

18. N. Wang, T. Hang, D. Chu, M. Li, Three-dimensional hierarchical nanostructured $\mathrm{Cu} / \mathrm{Ni}-\mathrm{Co}$ coating electrode for hydrogen evolution reaction in alkaline media. Nano-Micro Lett. 7(4), 347-352 (2015). doi:10.1007/s40820-015-0049-1

19. X. Li, P.F. Liu, L. Zhang, M.Y. Zu, Y.X. Yang, H.G. Yang, Enhancing alkaline hydrogen evolution reaction activity through $\mathrm{Ni}-\mathrm{Mn}_{3} \mathrm{O}_{4}$ nanocomposites. Chem. Commun. 52(69), 10566-10569 (2016). doi:10.1039/C6CC04141H

20. Q. Li, F. Wang, L. Sun, Z. Jiang, T. Ye, M. Chen, Q. Bai, C. Wang, X. Han, Design and synthesis of $\mathrm{Cu} @ \mathrm{CuS}$ yolk-shell structures with enhanced photocatalytic activity. Nano-Micro Lett. 9, 35 (2017). doi:10.1007/s40820-017-0135-7

21. X. Yan, L. Tian, J. Murowchick, X. Chen, Partially amorphized $\mathrm{MnMoO}_{4}$ for highly efficient energy storage and the hydrogen evolution reaction. J. Mater. Chem. A 4(10), 3683-3688 (2016). doi:10.1039/C6TA00744A

22. L. Shao, X. Qian, X. Wang, H. Li, R. Yan, L. Hou, Low-cost and highly efficient $\mathrm{CoMoS}_{4} / \mathrm{NiMoS}_{4}$-based electrocatalysts for hydrogen evolution reactions over a wide $\mathrm{pH}$ range. Electrochim. Acta 213, 236-243 (2016). doi:10.1016/j.electacta.2016.07.113

23. J. Luo, J.-H. Im, M.T. Mayer, M. Schreier, M.K. Nazeeruddin, N.-G. Park, S.D. Tilley, H.J. Fan, M. Grätzel, Water photolysis at $12.3 \%$ efficiency via perovskite photovoltaics and Earth-abundant catalysts. Science 345(6204), 1593-1596 (2014). doi:10.1126/ science. 1258307

24. J. Xing, H. Li, M. Ming-Cheng Cheng, S.M. Geyer, K.Y.S. Ng, Electro-synthesis of 3D porous hierarchical Ni-Fe phosphate film/Ni foam as a high-efficiency bifunctional electrocatalyst for overall water splitting. J. Mater. Chem. A 4(36), 13866-13873 (2016). doi:10.1039/C6TA05952J

25. A. Sivanantham, P. Ganesan, S. Shanmugam, Hierarchical $\mathrm{NiCo}_{2} \mathrm{~S}_{4}$ nanowire arrays supported on $\mathrm{Ni}$ foam: an efficient and durable bifunctional electrocatalyst for oxygen and hydrogen evolution reactions. Adv. Funct. Mater. 26(26), 4661-4672 (2016). doi:10.1002/adfm.201600566

26. D. Liu, Q. Lu, Y. Luo, X. Sun, A.M. Asiri, $\mathrm{NiCo}_{2} \mathrm{~S}_{4}$ nanowires array as an efficient bifunctional electrocatalyst for full water splitting with superior activity. Nanoscale 7(37), 15122-15126 (2015). doi:10.1039/C5NR04064G

27. B. Zhang, C. Xiao, S. Xie, J. Liang, X. Chen, Y. Tang, Ironnickel nitride nanostructures in situ grown on surface-redoxetching nickel foam: efficient and ultrasustainable electrocatalysts for overall water splitting. Chem. Mater. 28(19), 6934-6941 (2016). doi:10.1021/acs.chemmater.6b02610

28. B. You, N. Jiang, M. Sheng, M.W. Bhushan, Y. Sun, Hierarchically porous urchin-like $\mathrm{Ni}_{2} \mathrm{P}$ superstructures supported on nickel foam as efficient bifunctional electrocatalysts for overall water splitting. ACS Catal. 6(2), 714-721 (2016). doi:10.1021/ acscatal.5b02193
29. L.-L. Feng, G. Yu, Y. Wu, G.-D. Li, H. Li, Y. Sun, T. Asefa, W. Chen, X. Zou, High-index faceted $\mathrm{Ni}_{3} \mathrm{~S}_{2}$ nanosheet arrays as highly active and ultrastable electrocatalysts for water splitting. J. Am. Chem. Soc. 137(44), 14023-14026 (2015). doi:10.1021/ jacs.5b08186

30. G.-F. Chen, T.Y. Ma, Z.-Q. Liu, N. Li, Y.-Z. Su, K. Davey, S.-Z. Qiao, Efficient and stable bifunctional electrocatalysts Ni/NixMy $(\mathrm{M}=\mathrm{P}, \mathrm{S})$ for overall water splitting. Adv. Funct. Mater. 26(19), 3314-3323 (2016). doi:10.1002/adfm.201505626

31. C. Tang, N. Cheng, Z. Pu, W. Xing, X. Sun, NiSe Nanowire film supported on nickel foam: an efficient and stable 3D bifunctional electrode for full water splitting. Angew. Chem. Int. Ed. 127(32), 9483-9487 (2015). doi:10.1002/ange.201503407

32. R. Li, D. Zhou, J. Luo, W. Xu, J. Li, S. Li, P. Cheng, D. Yuan, The urchin-like sphere arrays $\mathrm{Co}_{3} \mathrm{O}_{4}$ as a bifunctional catalyst for hydrogen evolution reaction and oxygen evolution reaction. J. Power Sources 341, 250-256 (2017). doi:10.1016/j.jpowsour. 2016.10.096

33. W. Zhu, X. Yue, W. Zhang, S. Yu, Y. Zhang, J. Wang, J. Wang, Nickel sulfide microsphere film on $\mathrm{Ni}$ foam as an efficient bifunctional electrocatalyst for overall water splitting. Chem. Commun. 52(7), 1486-1489 (2016). doi:10.1039/C5CC08064A

34. R. Xu, R. Wu, Y. Shi, J. Zhang, B. Zhang, $\mathrm{Ni}_{3} \mathrm{Se}_{2}$ nanoforest/Ni foam as a hydrophilic, metallic, and self-supported bifunctional electrocatalyst for both $\mathrm{H}_{2}$ and $\mathrm{O}_{2}$ generations. Nano Energy 24, 103-110 (2016). doi:10.1016/j.nanoen.2016.04.006

35. X. Zhu, C. Tang, H.-F. Wang, B.-Q. Li, Q. Zhang, C. Li, C. Yang, F. Wei, Monolithic-structured ternary hydroxides as freestanding bifunctional electrocatalysts for overall water splitting. J. Mater. Chem. A 4(19), 7245-7250 (2016). doi:10.1039/C6TA02216B

36. Y. Rao, Y. Wang, H. Ning, P. Li, M. Wu, Hydrotalcite-like $\mathrm{Ni}(\mathrm{OH})_{2}$ nanosheets in situ grown on nickel foam for overall water splitting. ACS Appl. Mater. Interfaces 8(49), 33601-33607 (2016). doi:10.1021/acsami.6b11023

37. Z. Wang, S. Zeng, W. Liu, X. Wang, Q. Li, Z. Zhao, F. Geng, Coupling molecularly ultrathin sheets of NiFe-layered double hydroxide on $\mathrm{NiCo}_{2} \mathrm{O}_{4}$ nanowire arrays for highly efficient overall water-splitting activity. ACS Appl. Mater. Interfaces 9(2), 1488-1495 (2017). doi:10.1021/acsami.6b13075

38. Y. Yang, K. Zhang, H. Lin, X. Li, H.C. Chan, L. Yang, Q. Gao, $\mathrm{MoS}_{2}-\mathrm{Ni}_{3} \mathrm{~S}_{2}$ heteronanorods as efficient and stable bifunctional electrocatalysts for overall water splitting. ACS Catal. 7(4), 2357-2366 (2017). doi:10.1021/acscatal.6b03192

39. R. Miao, J. He, S. Sahoo, Z. Luo, W. Zhong et al., Reduced graphene oxide supported nickel-manganese-cobalt spinel ternary oxide nanocomposites and their chemically converted sulfide nanocomposites as efficient electrocatalysts for alkaline water splitting. ACS Catal. 7(1), 819-832 (2017). doi:10.1021/acscatal. 6b02650

40. J. Li, G. Wei, Y. Zhu, Y. Xi, X. Pan, Y. Ji, I.V. Zatovsky, W. Han, Hierarchical NiCoP nanocone arrays supported on $\mathrm{Ni}$ foam as an efficient and stable bifunctional electrocatalyst for overall water splitting. J. Mater. Chem. A 5, 14828-14837 (2017). doi: 10.1039/C7TA03947F

41. T. Tang, W.-J. Jiang, S. Niu, N. Liu, H. Luo et al., Electronic and morphological dual modulation of cobalt carbonate hydroxides by Mn doping toward highly efficient and stable bifunctional electrocatalysts for overall water splitting. J. Am. Chem. Soc. 139(24), 8320-8328 (2017). doi:10.1021/jacs.7b03507

42. Y. Wang, W. Wu, Y. Rao, Z. Li, N. Tsubaki, M. Wu, Cation modulating electrocatalyst derived from bimetallic metal-organic frameworks for overall water splitting. J. Mater. Chem. A 5(13), 6170-6177 (2017). doi:10.1039/C7TA00692F

43. L. Fang, W. Li, Y. Guan, Y. Feng, H. Zhang, S. Wang, Y. Wang, Tuning unique peapod-like $\mathrm{Co}\left(\mathrm{S}_{x} \mathrm{Se}_{1-x}\right)_{2}$ nanoparticles for 
efficient overall water splitting. Adv. Funct. Mater. 27(24), 1701008 (2017). doi:10.1002/adfm.201701008

44. X.-D. Wang, H.-Y. Chen, Y.-F. Xu, J.-F. Liao, B.-X. Chen, H.-S. Rao, D.-B. Kuang, C.-Y. Su, Self-supported $\mathrm{NiMoP}_{2}$ nanowires on carbon cloth as an efficient and durable electrocatalyst for overall water splitting. J. Mater. Chem. A 5(15), 7191-7199 (2017). doi:10.1039/C6TA11188B

45. J. Li, W. Xu, R. Li, J. Luo, D. Zhou, S. Li, P. Cheng, D. Yuan, A tremella-like $\mathrm{Ni}_{76} \mathrm{Co}_{24}$ layered double hydroxides nanosheets as an efficient catalyst for oxygen evolution reaction. J. Mater. Sci. 51(20), 9287-9295 (2016). doi:10.1007/s10853-016-0175-2

46. Y. Yang, Z. Lin, S. Gao, J. Su, Z. Lun, G. Xia, J. Chen, R. Zhang, Q. Chen, Tuning electronic structures of nonprecious ternary alloys encapsulated in graphene layers for optimizing overall water splitting activity. ACS Catal. 7(1), 469-479 (2017). doi:10. 1021/acscatal.6b02573

47. X. Fan, Z. Peng, R. Ye, H. Zhou, X. Guo, M3C (M: Fe Co, Ni) nanocrystals encased in graphene nanoribbons: an active and stable bifunctional electrocatalyst for oxygen reduction and hydrogen evolution reactions. ACS Nano 9(7), 7407-7418 (2015). doi:10.1021/acsnano.5b02420

48. J. Xu, J. Cui, C. Guo, Z. Zhao, R. Jiang et al., Ultrasmall $\mathrm{Cu}_{7-}$ $\mathrm{S}_{4} @ \mathrm{MoS}_{2}$ hetero-nanoframes with abundant active edge sites for ultrahigh-performance hydrogen evolution. Angew. Chem. Int. Ed. 55(22), 6502-6505 (2016). doi:10.1002/anie.201600686

49. A.-L. Wang, J. Lin, H. Xu, Y.-X. Tong, G.-R. Li, $\mathrm{Ni}_{2} \mathrm{P}-\mathrm{CoP}$ hybrid nanosheet arrays supported on carbon cloth as an efficient flexible cathode for hydrogen evolution. J. Mater. Chem. A 4(43), 16992-16999 (2016). doi:10.1039/C6TA07704H

50. Z. Wang, S. Xiao, Y. An, X. Long, X. Zheng, X. Lu, Y. Tong, S. Yang, $\mathrm{Co}(\mathrm{II})_{1-x} \mathrm{Co}(0)_{x / 3} \mathrm{Mn}(\mathrm{III})_{2 x / 3} \mathrm{~S}$ nanoparticles supported on $\mathrm{B} / \mathrm{N}$-codoped mesoporous nanocarbon as a bifunctional electrocatalyst of oxygen reduction/evolution for high-performance zinc-air batteries. ACS Appl. Mater. Interfaces 8(21), 13348-13359 (2016). doi:10.1021/acsami.5b12803

51. P. Chen, T. Zhou, M. Zhang, Y. Tong, C. Zhong, N. Zhang, L. Zhang, C. Wu, Y. Xie, 3D nitrogen-anion-decorated nickel sulfides for highly efficient overall water splitting. Adv. Mater. 29(30), 1701584 (2017). doi:10.1002/adma.201701584

52. Y. Wang, D. Liu, Z. Liu, C. Xie, J. Huo, S. Wang, Porous cobaltiron nitride nanowires as excellent bifunctional electrocatalysts for overall water splitting. Chem. Commun. 52(85), 12614-12617 (2016). doi:10.1039/C6CC06608A

53. F. Ming, H. Liang, H. Shi, X. Xu, G. Mei, Z. Wang, MOFderived Co-doped nickel selenide/C electrocatalysts supported on $\mathrm{Ni}$ foam for overall water splitting. J. Mater. Chem. A 4(39), 15148-15155 (2016). doi:10.1039/C6TA06496E

54. Y. Jin, X. Yue, C. Shu, S. Huang, P.K. Shen, Three-dimensional porous $\mathrm{MoNi}_{4}$ networks constructed by nanosheets as bifunctional electrocatalysts for overall water splitting. J. Mater. Chem. A 5(6), 2508-2513 (2017). doi:10.1039/C6TA10802D

55. Q. Li, Z. Xing, D. Wang, X. Sun, X. Yang, In situ electrochemically activated CoMn-S@NiO/CC nanosheets array for enhanced hydrogen evolution. ACS Catal. 6(7), 2797-2801 (2016). doi:10.1021/acscatal.6b00014

56. S.K. Jana, B. Saha, B. Satpati, S. Banerjee, Structural and electrochemical analysis of a novel co-electrodeposited $\mathrm{Mn}_{2} \mathrm{O}_{3}-\mathrm{Au}$ nanocomposite thin film. Dalton Trans. 44(19), 9158-91569 (2015). doi:10.1039/C5DT01025J

57. S. Li, P. Wang, J. Cheng, D. Luo, W. Zhou, J. Xu, R. Li, D.Yuan Li, High-performance flexible asymmetric supercapacitor based on CoAl-LDH and rGO electrodes. Nano-Micro Lett. 9, 31 (2017). doi:10.1007/s40820-017-0134-8

58. V.R. Stamenkovic, D. Strmcnik, P.P. Lopes, N.M. Markovic, Energy and fuels from electrochemical interfaces. Nat. Mater. 16(1), 57-69 (2016). doi:10.1038/nmat4738

59. Y. Liu, Q. Li, R. Si, G.-D. Li, W. Li et al., Coupling sub-nanometric copper clusters with quasi amorphous cobalt sulfide yields efficient and robust electrocatalysts for water splitting reaction. Adv. Mater. 29(13), 1606200 (2017). doi:10.1002/adma. 201606200

60. Y. Wu, G.-D. Li, Y. Liu, L. Yang, X. Lian, T. Asefa, X. Zou, Overall water splitting catalyzed efficiently by an ultrathin nanosheet-built, hollow $\mathrm{Ni}_{3} \mathrm{~S}_{2}$-based electrocatalyst. Adv. Funct. Mater. 26(27), 4839-4847 (2016). doi:10.1002/adfm.201601315

61. Y. Wu, Y. Liu, G.-D. Li, X. Zou, X. Lian, D. Wang, L. Sun, T. Asefa, X. Zou, Efficient electrocatalysis of overall water splitting by ultrasmall $\mathrm{NixCo}_{3-x} \mathrm{~S}_{4}$ coupled $\mathrm{Ni}_{3} \mathrm{~S}_{2}$ nanosheet arrays. Nano Energy 35, 161-170 (2017). doi:10.1016/j.nanoen.2017.03.024 